\title{
COMMUNICATING AND VALUING STUDENTS' PRODUCTIVE STRUGGLE AND CREATIVITY IN CALCULUS
}

\author{
Dennis B. ROBLE \\ Faculty of Department of Mathematics Education, College of Science and Technology Education, \\ University of Science and Technology of Southern Philippines, Cagayan de Oro City, Philippines \\ dennisroble@gmail.com
}

\begin{abstract}
Students' productive struggle in mathematics is described as the rigorous learning which can effectively promote grit and creative problem solving. This study aimed to determine and communicate students' perceptions on the struggle they experienced in their Calculus class, how this affects their learning and what mathematical tasks teachers need to develop to enhance students' level of achievement and creativity in Calculus. Survey questionnaires were handed to both engineering and mathematics education students and an experimental study was conducted during the first semester of school year 2016-17. In the analysis, students noted that they struggle because they need it for the program they are enrolled while others showed deeper understanding on how they can be productive after the effortful learning experiences. Further, the result of the experimental study showed that the problem-based Hawaii Algebra Learning Project (HALP) model problem solving and the pre-withinpost solution problem-posing activities revealed a positive effect on students' achievement and enhanced the level of students' mathematical creativity in terms of fluency, flexibility, and originality of their solutions in the Multiple Solutions Tasks (MST) test. Future researchers may consider utilizing these methods and exploring other strategies which could highly impact students' achievement level and creative ability in mathematics.
\end{abstract}

Keywords: Productive struggle, mathematical creativity, Multiple Solutions Tasks (MST) test, Problem-based Hawaii Algebra Learning Project (HALP) model, pre-within-post solution problem posing

\section{INTRODUCTION}

"Why do we have to struggle in calculus? Why calculus is a very difficult subject? I think I cannot survive this subject." The statements above shows students' indifference, opposition, dilemma and worries when they took up Calculus class, either in Differential or Integral Calculus. Despite these problems, students' need to pass Calculus because it is a very important subject for students in the Science, Technology, Engineering and Mathematics (STEM) programs. Calculus serves as an excellent tool in solving variety of problems and a key to key to understanding the systems of changes in society, biological, and the physical sciences. University students in the STEM programs believed that Calculus supplies a strong foundation in their analytical and computational skills which are deemed essential in the higher level mathematics. Calculus was considered as a gatekeeper and a roadblock to pursue their courses in the university and students' attrition rates became greater because passing rates in Calculus was minimal. Empirical studies and investigations was made by research scholars in the field to determine the causes of students' attrition, difficulty and conceptual misunderstandings of Calculus. Students' difficulty may be attributed to a number of reasons. Result showed from different studies have shown that students' background and experience in the prerequisites subjects could blocked students to learn deeply the concepts in Calculus (Maglipong, Roble \& Luna, 2015), high school GPA and admission test scores in mathematics (Jiang \& Freeman, 2011) and prior high school experience of the subject contributed to their success in Calculus (Gibson, 2013).

The National Council of Teachers of Mathematics (NCTM) Principles to Actions define productive struggle in mathematics as opportunities for delving more deeply into understanding the mathematical structure of problems and relationships among mathematical ideas, instead of simply seeking correct solutions (NCTM, 2014). Teachers who attend to the details of student thinking while teaching 
cognitively challenging math tasks build opportunities for productive struggle. They pay attention to the mathematical thinking needed, guide students with probing questions, and encourage student-tostudent discourse to support student understanding. Kang (2016) in Mind Research Institute blog site discussed the eight (8) teaching habits that block productive struggle in mathematics and these were the following:

(1) Calling on students who know the right answer;

(2) Praising students for their smarts;

(3) Creating bulletin boards to display high achievement;

(4) Focusing on teaching procedures and formulas;

(5) Marking student responses as right or wrong;

(6) Giving easier work to struggling students;

(7) Following a strict schedule for covering new material; and

(8) Making students feel ok about not being a "math person"

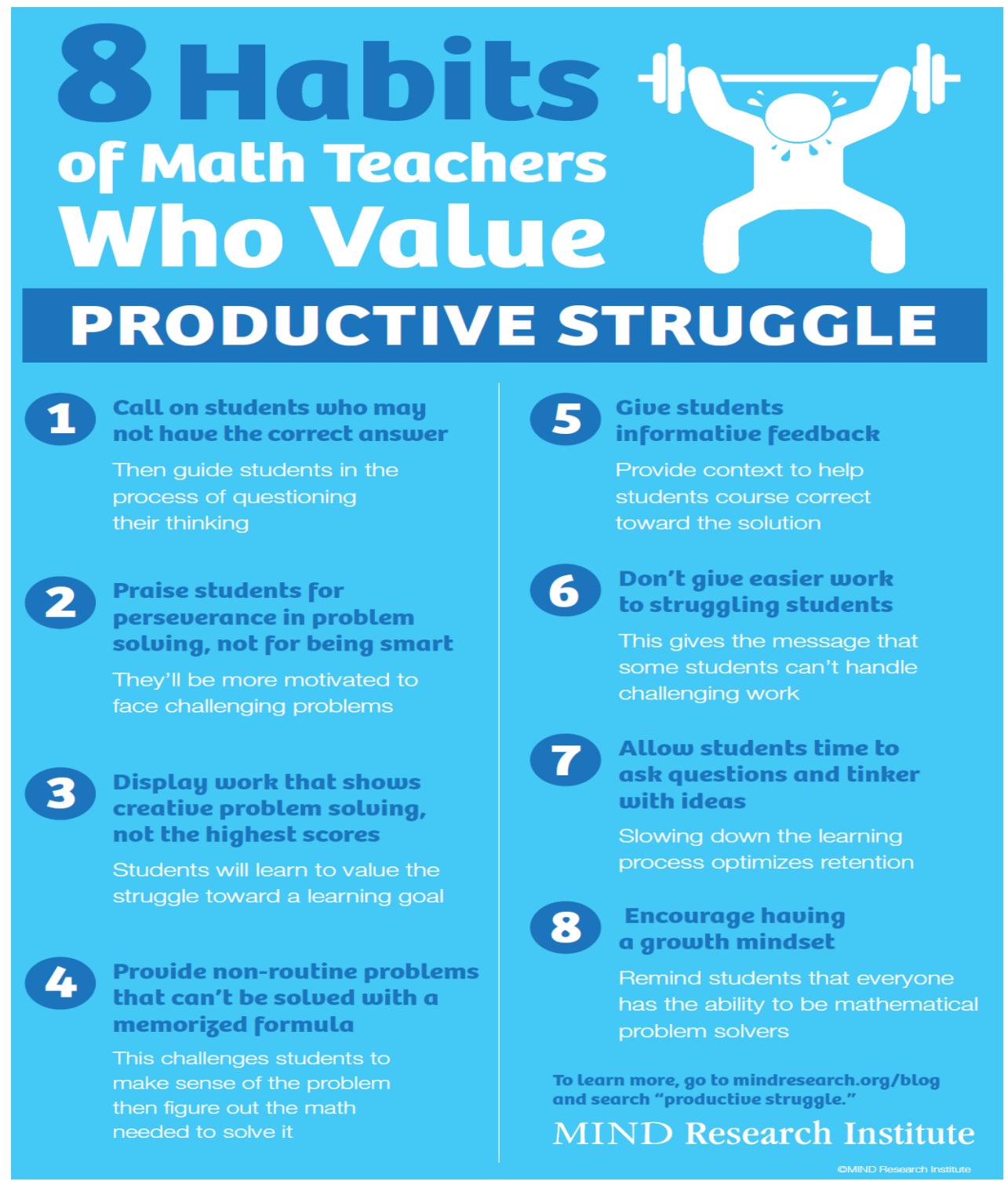

Image 1: 8 Habits of Math Teachers Who Value Productive Struggle

These eight teaching habits was always observed in many mathematics classes. In this way, teachers were actually not letting their students learn mathematics the hard way thus reducing the cognitive demand of the mathematical tasks and deprives students of opportunities to engage fully in making sense of mathematics. Toncheff \& Kanold (2014) in the Solution Tree blog showed an example of 
students and teachers actions in the process of productive struggle in mathematics classrooms. The sample was shown on the next page:

Table 1. Student and Teacher Actions in Productive Struggle

\begin{tabular}{|c|c|}
\hline $\begin{array}{l}\text { Student Actio } \\
\text { Productive }\end{array}$ & $\begin{array}{l}\text { Teacher Actions to Support } \\
\text { Productive Struggle }\end{array}$ \\
\hline $\begin{array}{l}\text { - Students look for entry points into the } \\
\text { task. } \\
\text { - Students list the given information and } \\
\text { describing the goal of the task. } \\
\text { - Students have choice in the solution } \\
\text { pathway and feel empowered by their } \\
\text { strategies. } \\
\text { - Students have a sense of hope as they } \\
\text { are struggling - they believe they can } \\
\text { conquer the task with effort } \\
\text { - Students say, "I think I got it and here } \\
\text { is why. Let me show you my way of } \\
\text { thinking." } \\
\text { - Students embrace their mistakes and } \\
\text { know that failure will produce a better } \\
\text { understanding of the task. } \\
\text { - Students keep trying even after several } \\
\text { failed attempts. }\end{array}$ & $\begin{array}{l}\text { - Collaborative teams work together to predict } \\
\text { any potential misconceptions and create } \\
\text { probing questions to get students "un-stuck" } \\
\text { (Kanold, et al., 2014) } \\
\text { - Teachers choose tasks that have multiple entry } \\
\text { points (low floor-high ceiling tasks). } \\
\text { Teachers create a community where students } \\
\text { know that it is okay to make mistakes. Wrong } \\
\text { strategies or solutions are analyzed and used } \\
\text { to promote understanding. } \\
\text { - Teachers provide ample time for students to } \\
\text { explore the task. } \\
\text { Teachers facilitate discussions around } \\
\text { misconceptions and asks, "Show me how you } \\
\text { know" or "prove it." } \\
\text { Teachers deliver growth-mindset messages as } \\
\text { students persevere through the task. }\end{array}$ \\
\hline
\end{tabular}

In a typical Calculus class, students struggle solving multi-faceted problems unlike previous mathematical studies except geometry. The solution of many problems will involve trigonometry, geometry and algebra and calculus.

COMMUNICATING STUDENTS' PERSPECTIVES ON THEIR STRUGGLE IN CALCULUS In order to solicit students' perspectives on the way they struggle in their Calculus classes, the researcher conducted a survey for both Engineering and Mathematics Education students taking up Differential Calculus in the current semester. A total of fifty (50) students participated in the survey and they were probed around five questions and their responses was recorded in the following table:

Table 2. Students' Responses in the Productive Struggle in Calculus Questionnaire

\begin{tabular}{|c|c|}
\hline Question & Responses \\
\hline $\begin{array}{l}\text { a) Why do you think Calculus is } \\
\text { an important subject? }\end{array}$ & $\begin{array}{l}\text { - They noted that Calculus is needed in real life, } \\
\text { related to their program and part of their } \\
\text { curriculum. } \\
\text { - The need for critical thinking and higher order } \\
\text { thinking skills is very high for Calculus and } \\
\text { once achieved they will have a better mind. } \\
\text { - Calculus was needed in their next upper level } \\
\text { mathematics subjects and also in other science } \\
\text { subjects which requires a skill in Calculus like } \\
\text { Physics. } \\
\text { For future mathematics educators, they feel the } \\
\text { need to master Calculus for them to be able to } \\
\text { teach the said subject in the future. }\end{array}$ \\
\hline $\begin{array}{l}\text { b) Are you struggling in your } \\
\text { Calculus subject? If you are }\end{array}$ & $\begin{array}{l}\text { - Majority of the respondents struggled in } \\
\text { Calculus most especially on the physical and }\end{array}$ \\
\hline
\end{tabular}




\begin{tabular}{|c|c|c|}
\hline & $\begin{array}{l}\text { struggling, in what specific } \\
\text { topic you find difficult? Why? }\end{array}$ & $\begin{array}{l}\text { geometric applications of Differential Calculus } \\
\text { such as optimization problems, rectilinear } \\
\text { motions, and related rates and among others. } \\
\text { - Other respondents noted that they found Chain } \\
\text { Rule for Derivatives difficult especially dealing } \\
\text { with trigonometric and inverse trigonometric } \\
\text { functions. } \\
\text { Some also showed difficulty in finding limits and } \\
\text { even understanding and applying the Squeeze } \\
\text { Theorem. }\end{array}$ \\
\hline c) & $\begin{array}{l}\text { Why do you think students' } \\
\text { need to struggle in this } \\
\text { subject? }\end{array}$ & $\begin{array}{l}\text { - Some respondents noted that they viewed the } \\
\text { struggle an important way to discipline or } \\
\text { sharpened the minds of students and develop } \\
\text { higher order thinking skills. } \\
\text { - Others pointed out that they are struggling now } \\
\text { for they will become prepared for real life } \\
\text { problems after graduation. } \\
\text { - A number of respondents also stressed the } \\
\text { importance of struggle to be prepared in the } \\
\text { next higher level mathematics and major } \\
\text { subjects. }\end{array}$ \\
\hline d) & $\begin{array}{l}\text { In your own thoughts, what } \\
\text { topics in Calculus discussed } \\
\text { you find very relevant in your } \\
\text { course? Why? }\end{array}$ & $\begin{array}{l}\text { - Most of them noted that they need the deep } \\
\text { understanding of derivatives. } \\
\text { - Others noted that all topics were relevant for } \\
\text { their course. } \\
\text { - Some respondents especially the Engineering } \\
\text { students noted the importance of the physical } \\
\text { and geometric applications of derivatives. }\end{array}$ \\
\hline e) & $\begin{array}{l}\text { What can you suggests to } \\
\text { teachers handling Calculus in } \\
\text { terms of delivery/manner of } \\
\text { presenting the topics? }\end{array}$ & $\begin{array}{l}\text { - The respondents noted that teachers need to } \\
\text { discuss Calculus topics slowly but surely because } \\
\text { they find the subject difficult to grasp. } \\
\text { - They also suggest that teachers need to present a } \\
\text { variety of examples to illustrate the concepts. } \\
\text { - Some of them stressed that teachers need to be } \\
\text { - patient and considerate in teaching Calculus. } \\
\text { Other respondents suggest that teachers need to } \\
\text { use a variety of teaching methods which would } \\
\text { effectively deliver the lessons well and be } \\
\text { understood deeply by students. } \\
\text { - They also want to have an integration of } \\
\text { technology in discussing the lessons. } \\
\text { They want also their teachers to discuss the step- } \\
\text { by-step process in discussing the topics, not } \\
\text { explaining too fast. } \\
\text { They also want their teacher to have a great deal } \\
\text { of patience and the discussion should not be } \\
\text { boring because the subject is already difficult. }\end{array}$ \\
\hline
\end{tabular}


MATHEMATICAL TASKS FOSTERING STUDENTS' CREATIVITY IN CALCULUS Philosophers summed up the emerging present world system in four principles, universalism, globalism, interdependence and creativity, while other contemporary scholars viewed creativity as the "cultural capital of the 21 st century" for it is among the most important and pervasive of all human activities (Sheridan-Rabideau, 2010). Creativity requires experimentation, formulation of new hypotheses and open possibilities. Britten (2012) attributed economic success to innovative thinking and he stated that creativity reduces inequalities and improves the quality of living. Therefore, creativity is one of the fundamental requirements to live in this present generation.

Contemporary schools need to prepare students to work in current workplaces and teachers must help students to develop these skills needed for success. Among the most important 21 st century skills which may help students adapt to the changing society is to develop their creativity and intellectual curiosity. Creativity is an integral part of mathematics. It is traditionally supposed to attribute to art and literature, but recently doing meaningful science has also been considered as a creative act. In mathematics classroom, students' who are creative seemed to possess the quality of a good problem solvers with excellent critical thinking skills which the present society needs. In relation to the teaching and learning of mathematics concepts, students need to possess creative thinking and problem solving skills and mathematics educators must also design activities which promotes creativity among students. Considering the importance of creativity, the task of mathematics educators is to design activities that can foster the development of students' mathematical creativity.

Mathematical creativity is difficult to develop if one is limited to rule-based applications without recognizing the requirement of the problem to be solved. The visionary classrooms as described by the National Council of Teachers of Mathematics (NCTM) enable students to confidently engage in complex mathematical task, draw knowledge from a wide variety of mathematical topics, approaching the same problem from different mathematical perspectives and representing the mathematics concepts in different ways until they find new methods that enable them to make progress. (NCTM, 2000).

In order to measure students' level of mathematical creativity, the open-ended Multiple Solutions Tasks (MST) test was designed. The responses of students will be evaluated according to the criteria based on the model suggested by Leiken (2013) as a combination of fluency, flexibility and novelty/originality. Fluency is the generation of different solutions, flexibility which entails the change of shift that take place in the emphasis, direction or approach and novelty refers to the level of originality in the development of new and unique solutions.

\section{Problem-based Hawaii Algebra Learning Project (HALP) Model and Polya's Four-step Heuristic Problem Solving Model Mathematical Tasks}

In the present age, it is necessary that students are critical thinkers and problem solvers. Some students would benefit from instructional strategies for problem solving. Like the parable, if you teach a man to fish he can fish for a lifetime. Likewise, if you teach a student how to solve problems in mathematics, they can do it for a lifetime. Problem solving as a method of teaching has long been recommended by leading educators. Research have substantiated its advantages and recommended that it should be part of the curriculum. Students are expected to take responsibility for their own learning and take personal action to solve problems, resolve conflicts, discuss alternatives, and focus their thinking as part of life. Creativity and problem solving are considered important building blocks to global and personal success in this present generation (Marshak 2003; Seo, Lee, \& Kim 2005, Sriraman 2005). Problem solving is considered to be one of the effective ways of developing creativity among students in mathematics. Chamberlin and Moon (2005) said that mathematical creativity is evident when a student is able to generate a new nonstandard solution to a problem which may not be solved using the standard method. Furthermore, when a student is able to solve an old problem in a new way, a student is considered creative. Aside from creativity, problem solving can promote communication, critical 
reflection, analysis, organization, experimentation, synthesis, generalization, validation, perseverance and systematic recording of information.

Problem-based instruction is an approach in teaching mathematics wherein the students have opportunities to consistently engage in problem solving, putting them in a thinking situation. Hawaii Algebra Learning Project (HALP) is an algebra program developed by the Curriculum Research and Development Group (CRDG) of the University of Hawaii. This algebra program changes the roles of the teachers and students. The students in their group do their own investigation to solve a problem and the teacher becomes the facilitator of the learning. HALP has been implemented at a variety of sites in 16 states in the US. The CRDG conducted an evaluation using a pretest and posttest normreference design to HALP students at three sites in Mississippi and one in Hawaii. The analysis of data revealed that students who participated in HALP performed significantly better than the comparison group. Thus, in the context of this research study, the researcher made an experiment using HALP in the treatment group and Polya's Four-Step Heuristic problem solving method in the control group. The analytical steps in the four-step heuristic methods are as follows:

A. Understanding the Problem. The students carefully reads the problem and decides what to do. This includes identifying the important data, the given, the condition and the unknown quantities.

B. Devising a Plan. Finding the connection between the data and the unknown and consider auxiliary problems if connections cannot be found to obtain a plan of the solution.

C. Carrying Out the Plan. Implementing a particular plan in solving the problem, revise and modify the plan as needed and create new plan if necessary.

D. Looking Back. Ensuring that all important information are used and decide whether or not the answer makes sense and checking all the given conditions of the problem were addressed by the answer.

\section{Pre-Within-Post Solution Problem Posing Activities in Mathematics}

Problem posing is recognized as an important component of mathematics teaching and learning (NCTM, 2000). Problem posing involves generation of new problems and questions aimed at exploring a given situation and reformulation of a problem during the process of solving. Several researchers assert that posing problems is an essential part of creative problem solving (Kim, 2009). Brinkman (2004) believes that if mathematics teachers want to bring mathematical beauty within students' experiences, they should utilize mathematical problems which are not only simple but also have certain complexity so that one can experience the aesthetic feeling of discovering in mathematics. Peressini and Knuth (2000) make use of mathematically rich tasks for enriching students' mathematical experiences and suggest a number of criteria which are required for such tasks to encourage a range of approaches to obtain solution, address significant mathematical concepts, require students to justify their explanations, and provide problems that are open ended. These tasks are similar to Multiple Solution Tasks (MST) considered by Leikin (2009). MST is a mathematical problem which requires many steps in order to arrive at a solution in different ways. Solutions to a certain problem are considered to be different if they are based on different representations of some mathematical concepts involved in the task, different properties (definitions or theorems) of mathematical objects within a particular field, or different process of a mathematical solutions (Leikin, 2009). In order to measure the level of problem posing skills, a rubric was created and the rubric was shown in the following table:

Table 3. Rubric for Pre-Within-Post Solution Problem Posing Activities

\begin{tabular}{|c|c|}
\hline Score & Descriptors \\
\hline 6 & Poses a more complex problem with two or more correct possible solutions, \\
\hline
\end{tabular}




\begin{tabular}{|c|l|}
\hline & $\begin{array}{l}\text { communicates ideas unmistakably, shows in-depth comprehension of the pertinent } \\
\text { concepts and/or processes, and provides explanations wherever appropriate. }\end{array}$ \\
\hline 5 & $\begin{array}{l}\text { Poses a more complex problems and finishes most significant parts of the solution, } \\
\text { communicates ideas mistakably, and shows in-depth comprehension of the pertinent } \\
\text { concepts and/or processes. }\end{array}$ \\
\hline 4 & $\begin{array}{l}\text { Poses a complex problem and finishes all significant parts of the solution, communicates } \\
\text { ideas mistakably, and shows in-depth comprehension of the pertinent concepts and/or } \\
\text { processes. }\end{array}$ \\
\hline 3 & $\begin{array}{l}\text { Poses a complex problem and finishes most significant parts of the solution, } \\
\text { communicates ideas unmistakably, and shows comprehension of major concepts although } \\
\text { neglects or misinterprets less significant ideas or details. }\end{array}$ \\
\hline 2 & $\begin{array}{l}\text { Poses a problem and finishes some significant parts of the solution and communicates } \\
\text { ideas mistakably but shows gaps on theoretical comprehension. }\end{array}$ \\
\hline 1 & $\begin{array}{l}\text { Poses a problem but demonstrates minor comprehension, not being able to develop an } \\
\text { approach. }\end{array}$ \\
\hline
\end{tabular}

\section{RESULTS \& FINDINGS OF THE EXPERIMENTAL STUDY}

The experimental study was conducted during the first semester of school year 2016-2017. The participants of the study were two intact classes in Differential Calculus were the treatment and control group was randomly chosen. The instruments such as the achievement test in Calculus and MST test was validated with reliability coefficient of 0.80 and 0.74 , respectively. The experiment run for five (5) months and the researcher served as the instructor for both groups to avoid bias and teacher factor effect. The results of the experiment was shown in the following tables:

Table 4. Level of Students Performance in the Multiple Solutions Tasks (MST) Test

\begin{tabular}{|c|c|c|c|c|c|c|c|c|}
\hline \multirow[t]{3}{*}{$\begin{array}{l}\text { Creativity } \\
\text { Indicators }\end{array}$} & \multicolumn{4}{|c|}{$\begin{array}{l}\text { Experimental Group } \\
(\mathrm{n}=45)\end{array}$} & \multicolumn{4}{|c|}{$\begin{array}{c}\text { Control Group } \\
(\mathrm{n}=45)\end{array}$} \\
\hline & \multicolumn{2}{|c|}{ Pretest } & \multicolumn{2}{|c|}{ Posttest } & \multicolumn{2}{|c|}{ Pretest } & \multicolumn{2}{|c|}{ Posttest } \\
\hline & Mean & SD & Mean & SD & Mean & SD & Mean & $\mathrm{SD}$ \\
\hline Fluency & 1.61 & 1.02 & 10.25 & 0.77 & 1.73 & 1.11 & 6.04 & 0.52 \\
\hline Flexibility & 5.23 & 2.54 & 11.89 & 1.09 & 5.34 & 2.13 & 7.44 & 1.66 \\
\hline Originality & 4.27 & 0.98 & 10.49 & 1.86 & 4.48 & 1.05 & 5.06 & 1.93 \\
\hline
\end{tabular}

It can be noted from the table that the experimental group showed greater increase in their mathematical creativity scores as compared to the control group. This implies that the HALP model in problem solving and the pre-within-post problem posing activities helped them developed their level of mathematical creativity. Before the experiment was conducted, it can be observed that the control group had a better level of fluency, flexibility and originality but after the experiment, they were overtaken by the scores of the experimental group. The standard deviations for both groups had a lesser spread in the pretest while it increases in the posttest. This result indicate that both groups showed quite similar spread in both the pretest and posttest.

Table 5. Students' Achievement Level in Calculus

\begin{tabular}{|c|c|c|c|c|c|}
\hline \multirow[t]{2}{*}{ Achievement } & Score & \multicolumn{2}{|c|}{$\begin{array}{l}\text { Experimental Group } \\
\quad(n=45)\end{array}$} & \multicolumn{2}{|c|}{$\begin{array}{l}\text { Control Group } \\
(\mathrm{n}=45)\end{array}$} \\
\hline & & Pretest & Posttest & Pretest & Posttest \\
\hline Mean & & 10.13 & 34.28 & 10.15 & 20.55 \\
\hline SD & & 1.29 & 3.66 & 1.67 & 4.07 \\
\hline
\end{tabular}

Perfect Score: 48 
Table 5 above shows similar abilities of both the experimental and control groups before the start of the experiment as indicated in their pretest scores. However, after the experiment, the treatment group grow up significantly as compared to the control group. This result implies that the mathematical tasks such as the HALP and problem posing activities was an effective strategy to improve students' level of achievement in Calculus. The standard deviations for both groups shows a lesser spread in the pretest while in the posttest, the experimental group showed a lesser spread as compared to the control group which means that they have more close likely the same scores.

\section{CONCLUSIONS AND RECOMMENDATIONS}

Based on the findings of this study, it can be inferred that students enrolled in Calculus were very communicative on their struggles and shortcomings but their level of awareness on the significance of learning the subject was very clear such as they were apprehnensive on the need to master the competencies since it would be applied in the upper level mathematics and most especially in their field of specialization. On this matter, students should be motivated to learn and in the end believe that their struggle was undeniably productive. Furthermore, students level of creative abilities could be developed effectively when they were exposed on problem-based and problem posing activities. In the case of this study, the problem-based HALP model and the pre-within-post problem posing revealed strong impact on their level of creativity as well as their achievement.

Mathematics classroom nowadays need to shift from traditional classroom to an environment where students will enjoy mathematics and develop not only their achievement level but at the same their creative potential, problem solving abilities and develop their higher order thinking skills. Teachers may design high cognitive demand mathematical tasks which allows students to struggle and at the same time be productive. The very purpose of their struggle in mathematics should lead them to deeper understanding of the concepts as well as enhancing their skills which they will need in the future workplace. Mathematics educators in the field are now challenged to be creative in their teaching, applying various strategies which could foster deeper and meaningful learning experiences for the students. The problem-based HALP model in problem solving and problem posing activities could be followed by teachers in the mathematics classrooms. It would be best if these strategies be integrated in the syllabus or daily lesson logs of teachers and further explorations of other mathematics tasks which could effectively foster and develop students' creative potential, achievement and better retention of concepts may be conducted by future researchers.

\section{REFERENCES}

Brinkmann, A. (2004): The Experience of Mathematical Beauty. ICME-10, The 10th International Congress on Mathematical Education, July 4-11, 2004, in Copenhagen, Denmark.

Britten, S. (2012). Can creativity fix South Africa? Mail \& Guardian Online.

Gibson, M. (2013). Motivation and Study Habits of College Calculus Students: Does Studying Calculus in High School Make a Difference?. ProQuest LLC. 789 East Eisenhower Parkway, PO Box 1346, Ann Arbor, MI 48106.

Jiang, X., \& Freeman, S. (2011). An analysis of the effect of cognitive factors on students' attritions in engineering: A literature review. In Proceedings of the American Society for Quality STEM agenda conference.

Kang, H. (2016). 8 Teaching Habits that Block Productive Struggle in Math Students. Retrieved from www.solution-tree.com/blog/how-do-you-make-struggling-productive.

Kim, K. H. (2009). Creative Problem Solving. In B. Kerr (Ed). Encyclopedia of Giftedness, Creativity and Talent. Sage Publications. . pp. 188-191. 
The Turkish Online Journal of Design, Art and Communication - TOJDAC April 2017 Volume 7 Issue 2

Leikin, R. (2009, 2013). Exploring mathematical creativity using multiple solution tasks. In R. Leikin, A. Berman \& B. Koichu (Eds.), Creativity in mathematics and the education of gifted students. (Ch. 9, pp. 129-145). Rotterdam, the Netherlands: Sense Publisher.

Marshak, D. (2003). No child left behind: A foolish race into the past. Phi Delta Kappan, 85, 229-231.

National Council of Teachers of Mathematics. (2000). Principles and standards for School mathematics. Reston, VA: National Council of Teacher of Mathematics.

NCTM, National Council of Teachers of Mathematics (2014). Principles to actions: Ensuring mathematical success for all. Reston, $V A$.

Peressini D., \& Knuth, E. (2000). The Role of Tasks in Developing Communities of Mathematical Inquiry. Teaching Children Mathematics,391-396

Seo, H.-A., Lee, E., \& Kim, K. (2005). Korean science teachers' understanding of creativity in Gifted Education. Journal of Secondary Gifted Education, XVI(2/3), 98-105.

Sheridan-Rabideau, M. (2010). Creativity repositioned. Arts Education Policy Review, 111, 54-58. doi:10.1080/10632910903455876.

Sriraman, B. (2005). Are gifted \& creativity synonyms in mathematics? An analysis of constructs within the profession and school realms. The Journal of Secondary Gifted Education, 17(1), 2036.

Toncheff, M., \& Kanold, T. (2014). Beyond the common core: A handbook for mathematics in a PLC at work. Bloomington, Indiana: Solution Tree. 